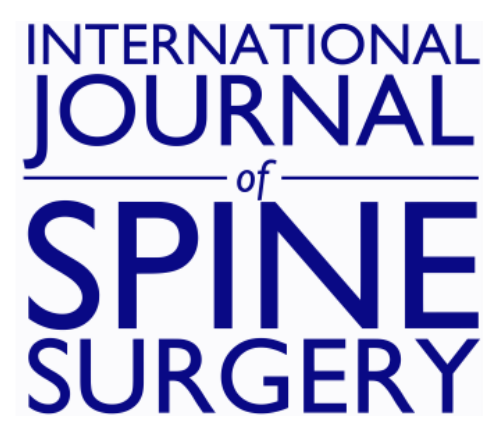

\title{
Expandable Technology Improves Clinical and Radiographic Outcomes of Minimally Invasive Lateral Lumbar Interbody Fusion for Degenerative Disc Disease
}

Yan Michael Li, Zheng Huang, James Towner, Yan Icy Li, Jessica R. Riggleman and Charles Ledonio

Int J Spine Surg 2021, 15 (1) 87-93

doi: https://doi.org/10.14444/8012

http://ijssurgery.com/content/15/1/87

This information is current as of April 26, 2023.

Email Alerts Receive free email-alerts when new articles cite this article. Sign up at: http://ijssurgery.com/alerts 


\title{
Expandable Technology Improves Clinical and Radiographic Outcomes of Minimally Invasive Lateral Lumbar Interbody Fusion for Degenerative Disc Disease
}

\author{
YAN MICHAEL LI, MD, PHD,${ }^{3}$ ZHENG HUANG, MD, PHD,${ }^{3}$ JAMES TOWNER, MD,${ }^{3}$ YAN ICY LI, PHD,${ }^{1,3}$ \\ JESSICA R. RIGGLEMAN, BS, ${ }^{4}$ CHARLES LEDONIO, MD, CCRP ${ }^{4}$ \\ ${ }^{I}$ Minimally Invasive Brain and Spine Institute University Spine and Neurosurgery, SUNY Upstate Medical University, Syracuse, $N Y,{ }^{2}$ Department of \\ Orthopaedics, Guanghua Hospital Shanghai Shi, China, ${ }^{3}$ Department of Neurosurgery, University of Rochester Medical Center School of Medicine and Dentistry, \\ Rochester, New York, ${ }^{4}$ Musculoskeletal Education and Research Center, A Division of Globus Medical, Inc, Audubon, Pennsylvania
}

\begin{abstract}
Background: Static interbody spacers are standard of care for minimally invasive lateral lumbar interbody fusion (MIS LLIF). However, placement of large static interbody spacers typically requires multiple trialing, endplate preparation, and forceful impaction. A lateral expandable interbody spacer with adjustable lordosis can be inserted at a reduced height, to optimize the endplate-to-endplate fit. This study describes radiographic and clinical outcomes in patients treated using lateral titanium expandable interbody spacers with adjustable lordosis using MIS LLIF.

Methods: This is a single-surgeon, retrospective, institutional review board-exempt chart review of 24 consecutive patients who underwent MIS LLIF at 1-2 contiguous level(s) using expandable spacers with adjustable lordosis. Radiographic and clinical functional outcomes were collected and compared at preoperative and postoperative time points up to 24 months. Parametric and nonparametric tests were used when appropriate. Statistical results were significant if $P<.05$.

Results: Twenty-four consecutive patients were evaluated with an average age of $57.8 \pm 12.6$ years; $45.8 \%$ were female. Visual analog scale for back pain improved by $7.3 \pm 1.0$ points, whereas Oswestry Disability Index scores improved by a mean of $67.5 \pm 11.3$ points at 24 months $(P<.001)$. Lumbar lordosis improved by a mean of $6.3 \pm 10.1^{\circ}$ at 24 months $(P<.001)$. There were 29 spinal levels, with $41.4 \%$ at L4-5 and $34.5 \%$ at L3-4. Anterior, middle, and posterior disc height significantly increased at 24 months by means of $4.5 \pm 2.9 \mathrm{~mm}, 4.0 \pm 2.8 \mathrm{~mm}$, and $2.6 \pm 1.9 \mathrm{~mm}$, respectively $(P<.001)$. Neuroforaminal height significantly improved by $3.3 \pm 3.9 \mathrm{~mm}$ at 24 months $(P<.001)$. Segmental lordosis improved by $3.6 \pm 3.0^{\circ}$ at 24 months.

Conclusions: This study showed significant positive clinical and radiographic outcomes for patients who underwent MIS LLIF using expandable interbody spacers with adjustable lordosis. Correction of sagittal alignment was achieved and maintained up to 2-year follow-up. The use of expandable spacers with adjustable lordosis was shown to be safe and effective in this cohort.
\end{abstract}

Level of Evidence: 3.

Minimally Invasive Surgery

Keywords: expandable, fusion, lateral lumbar interbody fusion, minimally invasive, surgery

\section{INTRODUCTION}

Various surgical techniques allow access to the disc space for lumbar interbody fusion, including transforaminal lumbar interbody fusion, anterior lumbar interbody fusion, and posterior lumbar interbody fusion. First described in 2006, lateral lumbar interbody fusion (LLIF) is an increasingly popular method of treating patients with spinal back and leg pain and may help minimize the risk of complications associated with traditional approaches. ${ }^{1-3}$
Maintaining and achieving sagittal alignment is a critical component to the success of the LLIF procedure because it is a significant predictor in

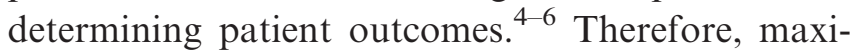
mizing disc and neuroforaminal height and maintaining proper lumbar and segmental lordosis are essential for adequate indirect decompression. Maintenance of sagittal alignment parameters may minimize adjacent segment degeneration. The development of adjacent segment disease (ASD) can occur by fusion of the lumbar spine in a hypolordotic alignment. ${ }^{7,8}$ Consequently, postoperative 


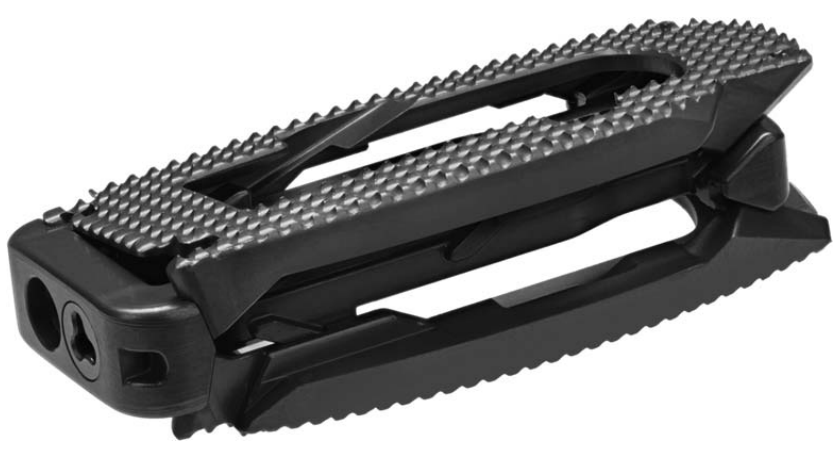

Figure 1. Expandable interbody spacer with adjustable lordosis.

sagittal plane abnormalities are correlated with ASD development. ${ }^{9}$

Numerous interbody spacer designs exist, some with built-in lordosis. The effects of increasing anterior lordosis without increasing disc height may have conflicting results. Godde et $\mathrm{al}^{10}$ describe the effects of interbody spacer design with or without built-in lordosis on segmental lordosis. Hyperlordotic interbody spacer designs could be challenging to insert in a collapsed disc space. One of the advantages of expandable interbody spacers is that the spacer is delivered in a collapsed state and expanded in situ. Developments in expandable technology allow for cages to increase in both height and lordosis through a controlled expansion. Long-term clinical outcome studies are needed to generate evidence of durability, effectiveness, and safety. The objective of this study is to determine the clinical and radiographic outcomes of patients who underwent MIS LLIF using an expandable interbody spacer with an adjustable lordosis.

This is a retrospective study from a prospectively collected cohort of patients diagnosed with symptomatic degenerative disc disease (DDD) with or without grade 1 spondylolisthesis in 1 or 2 contiguous levels, and who underwent MIS LLIF using a novel titanium expandable interbody spacer with adjustable lordosis with supplemental fixation (RISE-AL, Globus Medical, Inc, Audubon, PA) (Figures 1 and 2). Patient demographics, visual analog scale (VAS) back pain scores, Oswestry Disability Index (ODI) scores, and radiographic parameters were collected at 6 weeks, 3, 6, 12, and 24 months postoperatively.

\section{Surgical Technique}

After the induction of general anesthesia, patients were placed in the lateral decubitus position and
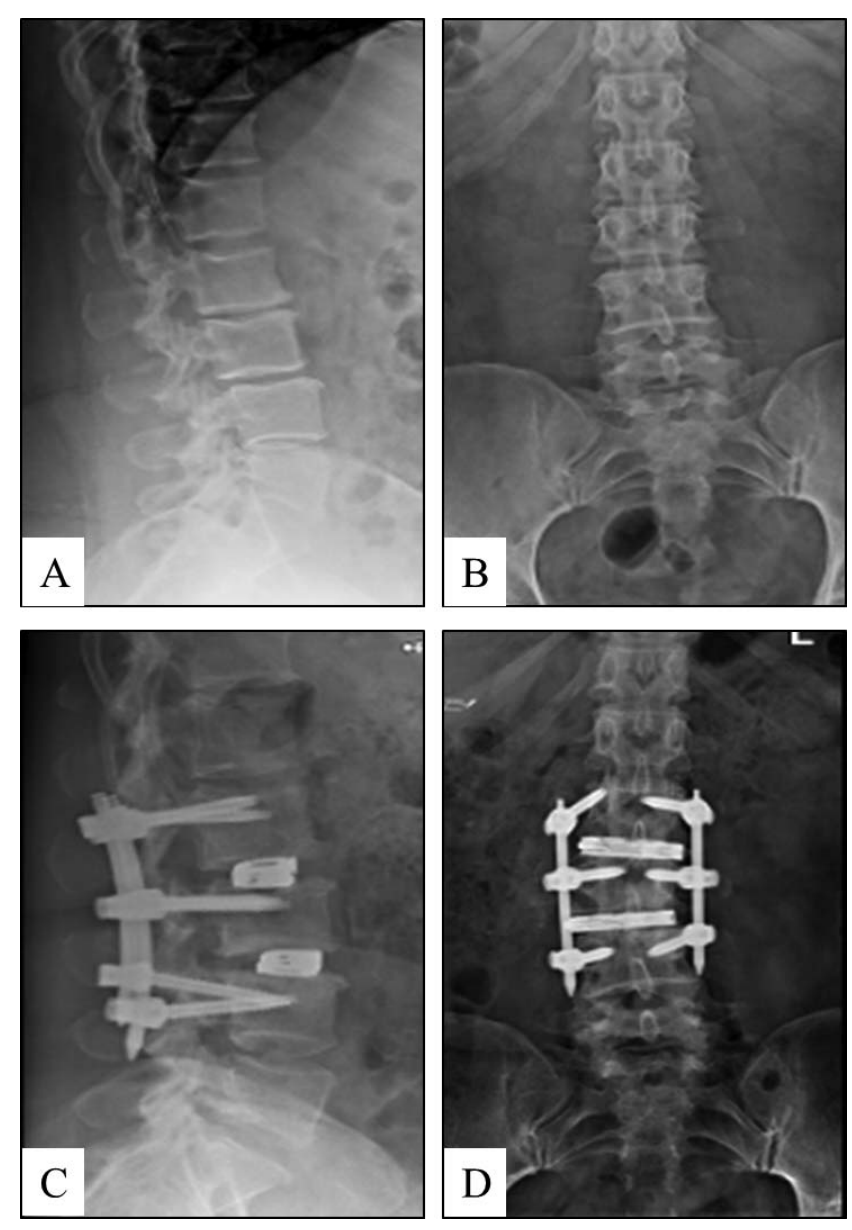

Figure 2. Preoperative lateral $(A)$ and anteroposterior $(B)$ radiographs and postoperative lateral $(C)$ and anteroposterior $(D)$ radiographs of a 2-level MIS LLIF using an adjustable lordotic expandable interbody spacer at L2-L3 and L3-L4. MIS LLIF, minimally invasive lateral lumbar interbody fusion.

secured to the operating table with adhesive medical tape. Under fluoroscopic guidance, an oblique incision was made at the operative disc segment. Blunt dissection was done under direct visualization through the retroperitoneal space. Retroperitoneal fat was mobilized anteriorly, exposing the underlying psoas muscle. The psoas muscle was palpated, and blunt dissection was performed down to the operative intervertebral disc level. After confirmation of the appropriate level via fluoroscopy, a minimally invasive retractor was docked, dilated at the segment, and secured to the table-mounted arm. An annulotomy was then performed, followed by a discectomy. Under fluoroscopic imaging, the endplates were prepared.

An expandable trial was used to allow for gradual distraction of the disc space. An expandable interbody spacer of appropriate size was selected, packed with autograft, and implanted laterally across the disc space. The spacer was then expanded 


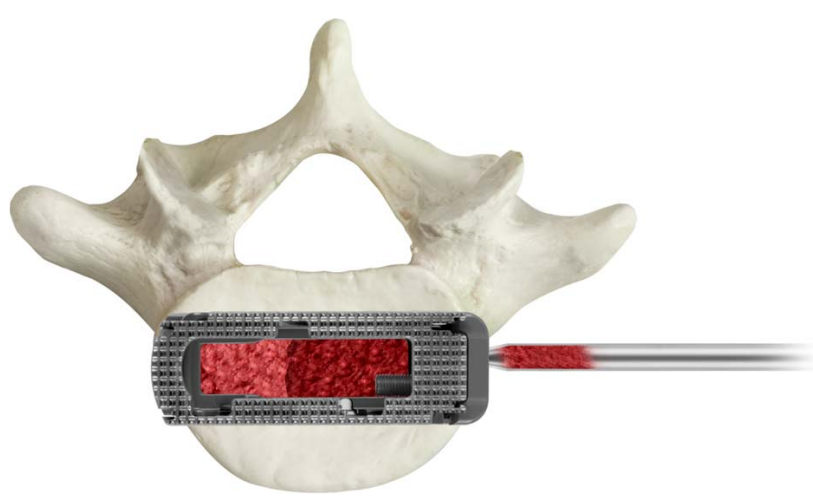

Figure 3. Additional bone graft may be packed into the graft chamber of the implant after expansion.

to the desired height and backfilled with autograft (Figure 3).

The expandable interbody spacer used in this study is manufactured from titanium alloy. The device is inserted at a contracted height and expanded in situ once correctly positioned within the intervertebral space, offering continuous expansion and adjustable lordosis for optimal endplateto-endplate contact.

Pedicle screws and rods were used for supplemental posterior fixation. Locking caps were set once the rods were in their proper position. Intraoperative fluoroscopy images were taken to verify screw and rod position. Surgical incisions were cleaned and closed in the standard fashion.

\section{Quantitative Measurements}

Radiographic lumbosacral parameters were measured on upright lateral radiographs using imaging software (Intellispace PACS 4.4; Koninklijke Philips N.V, Amsterdam, Netherlands) (Figure 4). Measurements included disc heights, neuroforaminal height, segmental lordosis, and lumbar lordosis. Disc height was defined as the distance between the inferior and superior endplates at the anterior, middle, and posterior portions of the vertebral body. Neuroforaminal height refers to the interpedicular height, or the rostral and caudal boundaries of the foramen. Segmental lordosis was measured as the Cobb angle of the superior endplate of the level below the LLIF and the inferior endplate of the level above the LLIF. Lumbar lordosis was measured as the angle between the superior endplate of L1 and the superior endplate of S1. Pseudoarthrosis and subsidence were assessed as previously described. $^{11,12}$

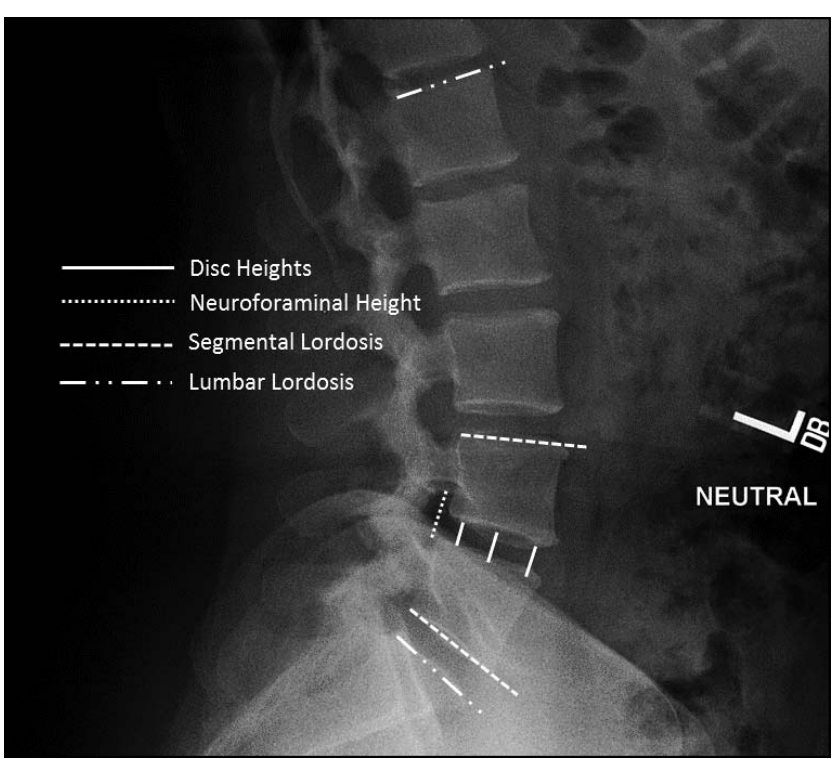

Figure 4. Standing lateral lumbar spine radiograph with superimposed lines displaying the measurements evaluated in this study. Measurements included disc heights, neuroforaminal height, segmental lordosis, and lumbar lordosis.

\section{Statistical Methods}

The statistical analysis was performed using IBM SPSS Version 25 (IBM Corp, Armonk, NY). Descriptive statistics are presented as frequencies and percentages. Clinical and radiographic measurements are presented as means and standard deviations. Statistical significance was shown at $P<$ .05 .

\section{RESULTS}

\section{Patient Demographics}

From August 2016 to January 2017, 24 consecutive patients underwent MIS LLIF with a titanium expandable interbody spacer with adjustable lordosis. The patients were $45.8 \%(11 / 24)$ female and $54.2 \%(13 / 24)$ male, with an average age of $57.8 \pm$ 12.6 years (range: 21-76 years). The average patients' Charlson Comorbidity Index (CCI) score was $2.6 \pm 2.1$ (range: $0-8)$ (Table 1$)$.

Table 1. Baseline characteristics.

\begin{tabular}{lc}
\hline Parameter & Overall \\
\hline Number of patients & 24 \\
Sex & \\
$\quad$ Female, n (\%) & $11(45.8)$ \\
$\quad$ Male, n (\%) & $13(54.2)$ \\
Age, mean (SD) (range) & $57.8(12.6)(21-76)$ \\
CCI, mean (SD) (range) & $2.6(2.1)(0-8)$ \\
\hline
\end{tabular}

Abbreviations: CCI, Charlson Comorbidity Index; SD, standard deviation. 
Table 2. MIS LLIF fusion procedure characteristics.

\begin{tabular}{lr}
\hline Parameter & Overall \\
\hline Type of surgery, n (\%) & \\
One-level & $19(79.2)$ \\
Two-level & $5(20.8)$ \\
Levels treated, n (\%) & $2(6.9)$ \\
L1-L2 & $5(17.2)$ \\
L2-L3 & $10(34.5)$ \\
L3-L4 & $12(41.4)$ \\
L4-L5 & $18.3(5.5)$ \\
Mean estimated blood loss, n (SD) & $31.0(6.5)$ \\
One-level & \\
Two-level & $53.9(14.2)$ \\
Mean operative time, n (SD) & $79.2(23.3)$ \\
One-level & \\
Two-level & $27.5(12.8)$ \\
Mean fluoroscopic time, n (SD) & $34.8(14.8)$ \\
One-level & \\
Two-level & $3.6(2.0)$ \\
Mean length of hospital stay, n (SD) & $6.0(4.1)$ \\
One-level & \\
Two-level & \\
\hline
\end{tabular}

Abbreviations: MIS LLIF, minimally invasive lateral lumbar interbody fusion; $\mathrm{SD}$, standard deviation

\section{Surgical Data}

Of the 24 patients, $79.2 \%$ (19/24) underwent 1level and 20.8\% (5/24) underwent 2-level MIS LLIF, for a total of 29 spinal levels treated. Of the 29 levels, $41.4 \%(12 / 29)$ were performed at L4-5 and 34.5\% $(10 / 29)$ at L3-4. The average estimated blood loss was $18.3 \pm 5.5 \mathrm{cc}$ for 1-level fusions and $31.0 \pm 6.5$ cc for 2-level fusions with no blood transfusions. The mean operative time was $53.9 \pm 14.2$ minutes for 1 level fusions and $79.2 \pm 23.3$ minutes for 2-level fusions. The mean fluoroscopic time was $27.5 \pm 12.8$ seconds for 1-level fusions and $34.8 \pm 14.8$ seconds for 2-level fusions. The mean length of hospital stay was $3.6 \pm 2.0$ days for 1-level fusions and $6.0 \pm 4.1$ days for 2-level fusions (Table 2).

\section{Patient-Reported Outcomes (VAS and ODI)}

Mean VAS back pain scores significantly improved from baseline by $51.2 \%(4.3 \pm 1.0), 61.9 \%$ $(5.2 \pm 1.1), 72.6 \%(6.0 \pm 1.2), 76.2 \%(6.4 \pm 1.6)$, and $86.9 \%(7.3 \pm 1.0)$ at 6 weeks, 3, 6, 12, and 24 months, respectively $(P<.001)$ (Figure 5). Mean ODI scores significantly improved from baseline by $38.1 \%(30.1 \pm 13.2), 55.6 \%(44.0 \pm 11.6), 65.7 \%$ $(52.0 \pm 14.6), 75.7 \%(59.9 \pm 16.1)$, and $85.3 \%(67.5$ $\pm 11.3)$ at 6 weeks, 3, 6, 12, and 24 months, respectively $(P<.001)$ (Figure 6; Table 3$)$.

\section{Radiographic Parameters}

The mean anterior disc height significantly improved from baseline by $85.9 \%(6.7 \pm 3.0 \mathrm{~mm})$,

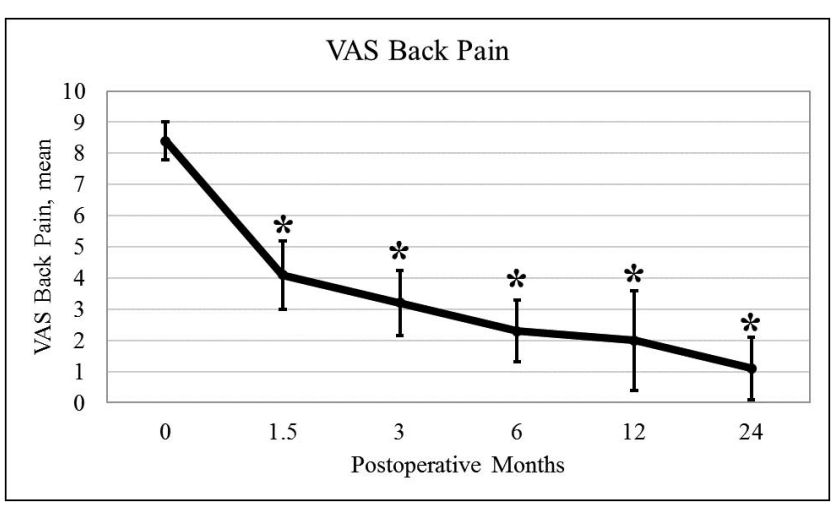

Figure 5. Mean VAS back pain is shown. The results show a significant decrease in VAS back pain scores from baseline and sustained at 1.5, 3, 6, 12, and 24 months. ${ }^{\star} P<.05$ compared with baseline. VAS, visual analog scale.

$78.2 \%(6.1 \pm 3.0 \mathrm{~mm}), 70.5 \%(5.5 \pm 3.0 \mathrm{~mm})$, $64.1 \%(5.0 \pm 3.0 \mathrm{~mm})$, and $57.7 \%(4.5 \pm 2.9 \mathrm{~mm})$ at 6 weeks, 3, 6, 12, and 24 months, respectively $(P$ $<.001)$. The mean middle disc height significantly improved from baseline by $93.8 \%(5.9 \pm 3.0 \mathrm{~mm})$, $78.1 \%(5.0 \pm 2.9 \mathrm{~mm}), 73.4 \%(4.7 \pm 2.8 \mathrm{~mm})$, $68.8 \%(4.4 \pm 2.9 \mathrm{~mm}), 64.1 \%(4.0 \pm 2.8 \mathrm{~mm})$ at 6 weeks, 3, 6, 12, and 24 months, respectively $(P<$ $.001)$. The mean posterior disc height significantly improved from baseline by $100.0 \%(4.4 \pm 1.8 \mathrm{~mm})$, $84.1 \%(3.7 \pm 1.8 \mathrm{~mm}), 75.0 \%(3.3 \pm 1.9 \mathrm{~mm})$, $63.6 \%(2.8 \pm 2.0 \mathrm{~mm})$, and $59.1 \%(2.6 \pm 1.9 \mathrm{~mm})$ at 6 weeks, 3, 6, 12, and 24 months, respectively ( $P$ $<.001)$. The mean neuroforaminal height significantly improved from baseline by $42.9 \%$ (6.3 \pm 3.9 $\mathrm{mm}), 37.4 \%(5.6 \pm 3.9 \mathrm{~mm}), 30.6 \%(4.6 \pm 4.2$ $\mathrm{mm}), 24.5 \%(3.6 \pm 4.0 \mathrm{~mm})$, and $22.4 \%(3.3 \pm 3.9$ $\mathrm{mm})$ at 6 weeks, 3, 6, 12, and 24 months, respectively $(P<.001)$. The mean segmental lordosis significantly improved from baseline by $113.6 \%\left(5.0 \pm 3.3^{\circ}\right), 102.3 \%\left(4.4 \pm 3.4^{\circ}\right), 95.5 \%$ $\left(4.2 \pm 3.3^{\circ}\right), 84.1 \%\left(3.6 \pm 3.1^{\circ}\right)$, and $81.8 \%(3.6 \pm$

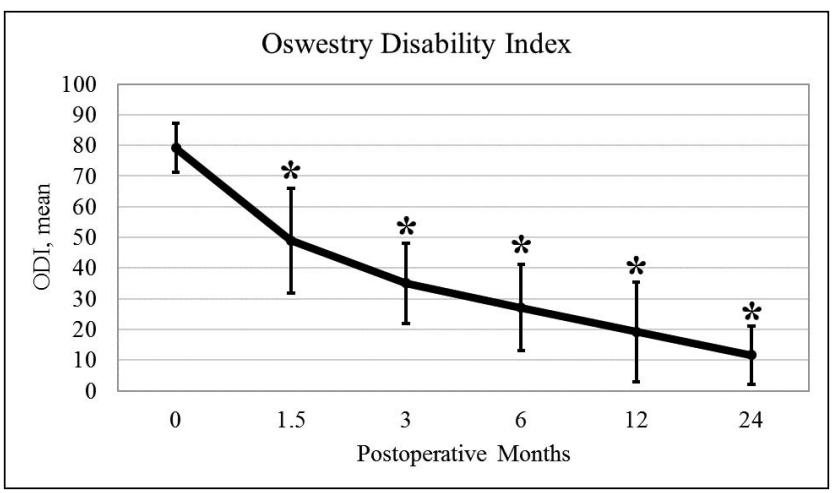

Figure 6. Mean ODI is shown. The results showed a significant decrease in ODI scores from baseline and sustained at 1.5, 3, 6, 12, and 24 months. ${ }^{*} P<$ .05 compared with baseline. ODI, Oswestry Disability Index. 
Table 3. Mean (standard deviation) values of patient reported outcomes and radiographic parameters.

\begin{tabular}{|c|c|c|c|c|c|c|}
\hline Parameter & Baseline & 6 Weeks & 3 Months & 6 Months & 12 Months & 24 Months \\
\hline VAS back pain & $8.4(0.6)$ & $4.1(1.1)^{\mathrm{a}}$ & $3.2(1.0)^{\mathrm{a}}$ & $2.3(1.0)^{\mathrm{a}}$ & $2.0(1.6)^{\mathrm{a}}$ & $1.1(1.0)^{\mathrm{a}}$ \\
\hline ODI & $79.1(8.0)$ & $49.0(17.1)^{\mathrm{a}}$ & $35.1(13.1)^{\mathrm{a}}$ & $27.1(14.1)^{\mathrm{a}}$ & $19.2(16.3)^{\mathrm{a}}$ & $11.6(9.5)^{\mathrm{a}}$ \\
\hline Anterior disc height, $\mathrm{mm}$ & $7.8(3.2)$ & $14.5(2.6)^{\mathrm{a}}$ & $13.9(2.6)^{\mathrm{a}}$ & $13.3(2.2)^{\mathrm{a}}$ & $12.8(2.0)^{\mathrm{a}}$ & $12.3(1.9)^{\mathrm{a}}$ \\
\hline Middle disc height, mm & $6.4(2.5)$ & $12.4(2.3)^{\mathrm{a}}$ & $11.4(2.6)^{\mathrm{a}}$ & $11.1(2.3)^{\mathrm{a}}$ & $10.8(2.2)^{\mathrm{a}}$ & $10.5(2.2)^{\mathrm{a}}$ \\
\hline Posterior disc height, $\mathrm{mm}$ & $4.4(1.7)$ & $8.8(2.0)^{\mathrm{a}}$ & $8.1(1.8)^{\mathrm{a}}$ & $7.7(1.6)^{\mathrm{a}}$ & $7.2(1.8)^{\mathrm{a}}$ & $7.0(1.7)^{\mathrm{a}}$ \\
\hline Neuroforaminal height, $\mathrm{mm}$ & $14.7(3.1)$ & $21.0(3.7)^{\mathrm{a}}$ & $20.2(3.5)^{\mathrm{a}}$ & $19.2(3.3)^{\mathrm{a}}$ & $18.3(3.2)^{\mathrm{a}}$ & $18.0(3.0)^{\mathrm{a}}$ \\
\hline Segmental lordosis, ${ }^{\circ}$ & $4.4(3.1)$ & $9.4(3.1)^{\mathrm{a}}$ & $8.9(3.0)^{\mathrm{a}}$ & $8.6(2.9)^{\mathrm{a}}$ & $8.1(2.3)^{\mathrm{a}}$ & $8.0(2.2)^{\mathrm{a}}$ \\
\hline Lumbar lordosis, $^{\circ}$ & $37.8(10.8)$ & $48.5(7.4)^{\mathrm{a}}$ & $47.5(5.0)^{\mathrm{a}}$ & $45.5(5.9)^{\mathrm{a}}$ & $44.4(5.6)^{\mathrm{a}}$ & $44.2(6.4)$ \\
\hline
\end{tabular}

Abbreviations: ODI, Oswestry Disability Index; VAS, visual analog scale.

${ }^{\mathrm{a}} P<.05$ compared with baseline.

$\left.3.0^{\circ}\right)$ at 6 weeks, 3, 6, 12, and 24 months, respectively $(P<.001)$. The mean lumbar lordosis significantly improved from baseline by $28.3 \%$ (10.7 $\left.\pm 10.6^{\circ}\right), 25.7 \%\left(9.7 \pm 9.3^{\circ}\right), 20.4 \%\left(7.6 \pm 9.7^{\circ}\right)$, and $17.5 \%\left(6.5 \pm 9.7^{\circ}\right)$ at 6 weeks, 3,6 , and 12 months, respectively $(P<.05)$. The mean lumbar lordosis improved from baseline by $16.9 \%$ (6.3 \pm $\left.10.1^{\circ}\right)$ at 24 months $(P>.05)$ (Table 3$)$.

\section{Complications}

There were no reported implant-related complications, radiolucency, or subsidence, and a $0 \%$ pseudoarthrosis rate by 24-month follow-up in this study group.

\section{DISCUSSION}

Long-term radiographic and clinical outcomes are essential to providing evidence that the use of lateral expandable interbody spacers with adjustable lordosis is effective. At 24-month follow-up, radiographic outcomes of this study showed that MIS LLIF using expandable interbody spacers with adjustable lordosis significantly corrected anterior, middle, and posterior disc height, neuroforaminal height, segmental lordosis, and lumbar lordosis by $57.7 \%, 64.1 \%, 59.1 \%, 22.4 \%, 81.8 \%$, and $16.9 \%$, respectively. At 24-month follow-up, VAS back and leg pain scores and ODI scores improved by $86.9 \%$ and $85.3 \%$, respectively.

To the best of the authors' knowledge, this is the first study to describe the long-term clinical and radiographic outcomes of the use of an expandable interbody spacer with an adjustable lordosis in MIS LLIF; therefore, comparison to the literature can be challenging.

In the treatment of DDD with or without spondylolisthesis, the loss of disc height and lumbar lordosis can cause debilitating back pain. ${ }^{13-15}$ Studies have shown that restoration and mainte- nance of these parameters after spine surgery is associated with improved clinical outcomes. . $^{3,10,16-18}$

Isaacs et $\mathrm{al}^{18}$ reported on radiographic outcomes of patients who underwent MIS TLIF (transforaminal lumbar interbody fusion) or MIS XLIF (extreme lateral interbody fusion [XLIF; NuVasive, Inc, San Diego, CA]) with static interbody spacers in the treatment of degenerative spondylolisthesis with stenosis through 2-year follow-up. Disc height was measured as the average of anterior and posterior disc heights. Disc height significantly increased by $2.5 \mathrm{~mm}(32.9 \%)$ and $2.4 \mathrm{~mm} \mathrm{(35.8 \% )}$ in the XLIF and MIS TLIF groups from baseline to 24 months, respectively. Lumbar lordosis increased by $0.2^{\circ}(0.3 \%)$ in the XLIF group and decreased by $2.6^{\circ}(4.4 \%)$ in the TLIF group from baseline to 24 months. To directly compare with the current study, anterior and posterior disc height were averaged and resulted in an increase of $3.6 \mathrm{~mm}(59.0 \%)$, whereas lumbar lordosis increased by $6.4^{\circ}(14.5 \%)$ from baseline to 24 months. Expandable titanium interbody spacers with adjustable lordosis may provide greater correction in the lumbar spine due to less endplate destruction and optimal fit after expansion in comparison with static interbody spacers.

Clinical outcomes were reported in a separate manuscript. ${ }^{17}$ VAS back pain scores significantly decreased by 5.4 points in the XLIF group and 3.6 points in the TLIF group at 24 months. In the current study, a greater decrease in VAS back pain scores by 7.3 points at 24 months was observed. Titanium expandable interbody spacers with adjustable lordosis for LLIF may provide improved indirect decompression leading to less postoperative pain compared with static interbody spacers in XLIF and TLIF.

The findings on radiographic and clinical outcomes were similarly improved in studies analyzing interbody spacers using MIS LLIF. Kotwal et $\mathrm{al}^{3}$ reported on 118 patients who underwent MIS LLIF 
with a minimum of 2 years' follow-up. VAS back pain scores significantly improved by 4.6 points and ODI scores improved by 12.9 points by 24 months. In a recent study, Frisch et $\mathrm{al}^{16}$ reported on 27 patients who underwent MIS LLIF with a PEEK (polyether ether ketone) expandable spacer. VAS back pain scores significantly improved by 3.1 points, whereas ODI scores significantly improved by 19.3 points.

The use of lordotic interbody spacers has been demonstrated in previous studies. In a comparative radiographic analysis of consecutive LLIF procedures using $10^{\circ}$ PEEK lordotic and nonlordotic interbody spacers, Sembrano et $\mathrm{al}^{19}$ found that lordotic cages significantly increased operative level segmental lordosis by $2.8^{\circ}$ compared with nonlordotic interbody spacers, with a nonsignificant improvement of $0.6^{\circ}$. In the current study, operative level segmental lordosis significantly improved by $3.6^{\circ}$, suggesting a larger improvement in titanium expandable interbody spacer with adjustable lordosis compared with the static PEEK lordotic spacers with a fixed $\left(10^{\circ}\right)$ lordosis.

In a prospective review, it was determined that minimal clinical important difference (MCID) values are 1.2 points for back pain and 12.8 points for ODI. ${ }^{20,21}$ In the current study, VAS back pain scores significantly improved by $4.3,5.2,6.1,6.4$, and 7.3 points at 6 weeks, 3, 6, 12, and 24 months, respectively. ODI scores significantly improved by $30.1,44,52,59.9$, and 67.5 points, respectively. This demonstrates a significant clinical benefit, with a mean VAS improvement of 3-6 times the MCID and a mean ODI improvement of 2-5 times the MCID. ${ }^{20,21}$

Subsidence rates with the use of static interbody spacers have been reported to be relatively high. In a systematic review by Macki et al, ${ }^{22}$ the pooled subsidence rate with LLIF was $10.3 \%$, with a range of $0 \%$ to as high as $30 \%(n=141 / 1362$ patients in 14 published articles) and a reoperation rate for subsidence of $2.7 \%(\mathrm{n}=41 / 1470$ patients in 16 published articles). In this review, the studies with the highest subsidence rates were from Marchi et $\mathrm{al},{ }^{23}$ with a rate of $29.7 \%$. Marchi et al, ${ }^{24}$ Pimenta et $\mathrm{al}^{25}$ and Le et $\mathrm{al}^{26}$ reported a subsidence rate of $17.2 \%, 16.6 \%$, and $14.3 \%$, respectively. Static polyetheretherketone spacers of various sizes were used in these studies. In the current study, there was no subsidence reported.

\section{Study Limitations}

Although this is a single-surgeon, single-site retrospective study with a small patient population, the results are consistent with findings from the literature. Comparative studies are needed to determine effectiveness to traditional treatment.

\section{CONCLUSION}

LLIF using an expandable titanium interbody spacer with adjustable lordosis is shown to be durable, safe, and effective at improving radiographic and clinical outcomes in this cohort. Anterior and posterior disc height and neuroforaminal height were significantly restored, providing evidence for indirect decompression. Segmental and lumbar lordosis were significantly restored, correcting sagittal alignment. There were no cases of subsidence up to 24-month follow-up.

\section{ACKNOWLEDGMENTS}

Funding for this project was provided by the Musculoskeletal Education and Research Center (MERC), a Division of Globus Medical, Inc. The authors thank Mr Howard Whitman and Ms Leigh Ahrendtsen for their hard work.

\section{REFERENCES}

1. Ozgur BM, Aryan HE, Pimenta L, Taylor WR. Extreme lateral interbody fusion (XLIF): a novel surgical technique for anterior lumbar interbody fusion. Spine J. 2006;6(4):435-443.

2. Lehmen JA, Gerber EJ. MIS lateral spine surgery: a systematic literature review of complications, outcomes, and economics. Eur Spine J. 2015;24(suppl 3):287-313.

3. Kotwal S, Kawaguchi S, Lebl D, et al. Minimally invasive lateral lumbar interbody fusion: clinical and radiographic outcome at a minimum 2-year follow-up. J Spinal Disord Tech. 2015;28(4):119-125.

4. Glassman SD, Berven S, Bridwell K, Horton W, Dimar JR. Correlation of radiographic parameters and clinical symptoms in adult scoliosis. Spine (Phila Pa 1976). 2005;30(6):682-688.

5. Glassman SD, Bridwell K, Dimar JR, Horton W, Berven $\mathrm{S}$, Schwab F. The impact of positive sagittal balance in adult spinal deformity. Spine (Phila Pa 1976). 2005;30(18):20242029.

6. Rodgers JA, Gerber EJ, Lehmen JA, Rodgers BW. Clinical and radiographic outcome in less invasive lumbar fusion: XLIF at two year follow-up. J Spine Neurosurg. 2013;2:1-6.

7. Chen WJ, Lai PL, Tai CL, Chen LH, Niu CC. The effect of sagittal alignment on adjacent joint mobility after lumbar instrumentation - a biomechanical study of lumbar vertebrae in a porcine model. Clin Biomech (Bristol, Avon). 2004;19(8):763768.

8. Djurasovic MO, Carreon LY, Glassman SD, Dimar JR 
2nd, Puno RM, Johnson JR. Sagittal alignment as a risk factor for adjacent level degeneration: a case-control study. Orthopedics. 2008;31(6):546.

9. Kumar MN, Baklanov A, Chopin D. Correlation between sagittal plane changes and adjacent segment degeneration following lumbar spine fusion. Eur Spine J. 2001;10(4):314-319.

10. Godde S, Fritsch E, Dienst M, Kohn D. Influence of cage geometry on sagittal alignment in instrumented posterior lumbar interbody fusion. Spine (Phila Pa 1976). 2003;28(15):1693-1699.

11. Kanemura T, Matsumoto A, Ishikawa $\mathrm{Y}$, et al. Radiographic changes in patients with pseudarthrosis after posterior lumbar interbody arthrodesis using carbon interbody cages: a prospective five-year study. J Bone Joint Surg Am. 2014;96(10):e82.

12. Choi JY, Sung KH. Subsidence after anterior lumbar interbody fusion using paired stand-alone rectangular cages. Eur Spine J. 2006;15(1):16-22.

13. Scemama C, Magrino B, Gillet P, Guigui P. Risk of adjacent-segment disease requiring surgery after short lumbar fusion: results of the French Spine Surgery Society Series. $J$ Neurosurg Spine. 2016;25(1):46-51.

14. Virk SS, Niedermeier S, Yu E, Khan SN. Adjacent segment disease. Orthopedics. 2014;37(8):547-555.

15. Zhu G, Hao Y, Yu L, Cai Y, Yang X. Comparing stand-alone oblique lumbar interbody fusion with posterior lumbar interbody fusion for revision of rostral adjacent segment disease: a STROBE-compliant study. Medicine. 2018;97(40):e12680.

16. Frisch RF, Luna IY, Brooks DM, Joshua G, O'Brien JR. Clinical and radiographic analysis of expandable versus static lateral lumbar interbody fusion devices with two-year follow-up. J Spine Surg. 2018;4(1):62-71.

17. Sembrano JN, Tohmeh A, Isaacs R. Two-year comparative outcomes of MIS lateral and MIS transforaminal interbody fusion in the treatment of degenerative spondylolisthesis: part I: clinical findings. Spine (Phila Pa 1976). 2016;41(suppl 8):S123-S132.

18. Isaacs RE, Sembrano JN, Tohmeh AG. Two-year comparative outcomes of MIS lateral and MIS transforaminal interbody fusion in the treatment of degenerative spondylolisthesis: part II: radiographic findings. Spine (Phila Pa 1976). 2016;41(suppl 8):S133-S144.

19. Sembrano JN, Horazdovsky RD, Sharma AK, Yson SC, Santos ERG, Polly DW Jr. Do lordotic cages provide better segmental lordosis versus nonlordotic cages in lateral lumbar interbody fusion (LLIF)? Clin Spine Surg. 2017;30(4):E338E343.

20. Copay AG, Glassman SD, Subach BR, Berven S, Schuler TC, Carreon LY. Minimum clinically important difference in lumbar spine surgery patients: a choice of methods using the Oswestry Disability Index, Medical Outcomes Study questionnaire Short Form 36, and pain scales. Spine $J$. 2008;8(6):968-974.

21. Copay AG, Subach BR, Glassman SD, Polly DW Jr, Schuler TC. Understanding the minimum clinically important difference: a review of concepts and methods. Spine $J$. 2007;7(5):541-546.

22. Macki M, Anand SK, Surapaneni A, Park P, Chang V. Subsidence rates after lateral lumbar interbody fusion: a systematic review. World Neurosurgery. 2019;122:599-606.

23. Marchi L, Abdala N, Oliveira L, Amaral R, Coutinho E, Pimenta L. Radiographic and clinical evaluation of cage subsidence after stand-alone lateral interbody fusion. $J$ Neurosurg Spine. 2013;19(1):110-118.

24. Marchi L, Abdala N, Oliveira L, Amaral R, Coutinho E, Pimenta L. Stand-alone lateral interbody fusion for the treatment of low-grade degenerative spondylolisthesis. Scientific WorldJournal. 2012;2012:456346.

25. Pimenta L, Marchi L, Oliveira L, Coutinho E, Amaral R. A prospective, randomized, controlled trial comparing radiographic and clinical outcomes between stand-alone lateral interbody lumbar fusion with either silicate calcium phosphate or rh-BMP2. J Neurol Surg A Cent Eur Neurosurg. 2013;74(6):343-350.

26. Le TV, Baaj AA, Dakwar E, et al. Subsidence of polyetheretherketone intervertebral cages in minimally invasive lateral retroperitoneal transpsoas lumbar interbody fusion. Spine (Phila Pa 1976). 2012;37(14):1268-1273.

Disclosures and COl: Yan Michael Li, Zheng Huang, and Yan Icy Li receive research support from the device company whose technology is examined in the paper. Jessica R. Riggleman and Charles Ledonio are employees of a company involved in the manufacture of a device examined in this study.

Corresponding Author: Yan Michael Li, $\mathrm{MD}, \mathrm{PhD}$, Minimally Invasive Brain and Spine Institute, University Spine and Neurosurgery, 739 Irving Ave \#600, Syracuse, NY 13210; Phone: (585) 678-1198; Email: Dr.Yanli@gmail.com.

Published 26 February 2021

This manuscript is generously published free of charge by ISASS, the International Society for the Advancement of Spine Surgery. Copyright (C) 2021 ISASS. To see more or order reprints or permissions, see http://ijssurgery.com. 